\title{
Nanoparticles of zinc oxide defeat chlorpyrifos-induced immunotoxic effects and histopathological alterations
}

\author{
Sara S. Essa ${ }^{1}$, Eiman M. El-Saied ${ }^{2}$, Osama S. El-Tawil ${ }^{2}$, Inas M. Gamal ${ }^{1}$ and Sahar S. Abd El-Rahman ${ }^{3}$
}

1. Immune Section, Research Institute for Animal Reproduction, Cairo, Egypt; 2. Department of Toxicology, Forensic Medicine and Veterinary Regulations, Faculty of Veterinary Medicine, Cairo University, Egypt; 3. Department of Pathology, Faculty of Veterinary Medicine, Cairo University, Cairo, Egypt.

Corresponding author: Sahar S. Abd El-Rahman, e-mail: saharsamirmah@cu.edu.eg Co-authors: SSE: sara_yn79@yahoo.com,EME: eman_moustafa84@yahoo.com, OSE: osamaeltawil@cu.edu.eg, IMG: inasgamal@yahoo.com

Received: 02-12-2018, Accepted: 28-01-2019, Published online: 22-03-2019

doi: 10.14202/vetworld.2019.440-448 How to cite this article: Essa SS, El-Saied EM, El-Tawil OS, Gamal IM, Abd ElRahman SS (2019) Nanoparticles of zinc oxide defeat chlorpyrifos-induced immunotoxic effects and histopathological alterations, Veterinary World, 12(3): 440-448.

\begin{abstract}
Background and Aim: Chlorpyrifos (CPF) is a widely used organophosphate insecticide. Nanoparticles of zinc oxide (ZnO NPs) physically showed effective adsorbing property for some insecticides. The study was conducted to estimate the potential effect of ZnO NPs against CPF toxicity.

Materials and Methods: Four groups of male rats were used; control group and three groups received drinking water contained $75 \mathrm{mg} / \mathrm{L} \mathrm{CPF}$, combined $75 \mathrm{mg} / \mathrm{L} \mathrm{CPF}$ and $200 \mathrm{mg} / \mathrm{L} \mathrm{ZnO}$ NPs, and $200 \mathrm{mg} / \mathrm{L} \mathrm{ZnO}$ NPs, respectively.

Results: CPF significantly decreased macrophage activity, serum lysozyme activity, and levels of interleukin-2 (IL-2) and IL-6; increased the percentage of DNA degeneration on comet assay of lymphocytes and significantly elevated hepatic and splenic malondialdehyde contents; and decreased their glutathione contents. The liver and spleen showed marked histological alterations after exposure to CPF with decreased expression of acetylcholinesterase. The coadministration of $\mathrm{ZnO}$ NPs ameliorated most of the undesirable effects of CPF, through elevation of macrophage and serum lysozyme activities, increased the levels of IL-2 and IL-6, corrected the oxidative stress markers, and alleviated most of the adverse effect exerted by CPF in liver and spleen tissues.
\end{abstract}

Conclusion: The addition of $\mathrm{ZnO}$ NPs to CPF-contaminated drinking water may be useful as a powerful antioxidant agent against toxic damage induced by CPF particularly in individuals who are on daily occupational exposure to low doses of CPF.

Keywords: acetylcholinesterase, chlorpyrifos, immune system, pathology, zinc oxide nanoparticles.

\section{Introduction}

Commercial insecticides used in agricultural and non-agricultural purposes have the potential to cause significant human and animal illnesses through direct or indirect exposure during application. Due to the extensive use of insecticides, they persist in soil, surface waters, air, and agricultural products [1]. Chlorpyrifos (CPF) is a well-known organophosphorothioate insecticide that is used for agricultural and non-agricultural areas. It is a broad-spectrum insecticide used to kill a wide range of insects [2,3]. CPF inhibits acetylcholinesterase (ACHE) enzyme of the nervous system necessary for proper function of the nervous system. Symptoms associated with the CPF poisoning including; nausea, vomiting, diarrhea, headache, convulsions, coma, and death in severe conditions. Long period exposure to $\mathrm{CPF}$ results in

Copyright: Essa, et al. Open Access. This article is distributed under the terms of the Creative Commons Attribution 4.0 International License (http://creativecommons.org/licenses/by/4.0/), which permits unrestricted use, distribution, and reproduction in any medium, provided you give appropriate credit to the original author(s) and the source, provide a link to the Creative Commons license, and indicate if changes were made. The Creative Commons Public Domain Dedication waiver (http://creativecommons.org/ publicdomain/zero/1.0/) applies to the data made available in this article, unless otherwise stated. serious harm effects to the nervous system, respiratory tract, and cardiovascular systems. CPF metabolites persist in the environment for a long period; therefore, it becomes a public concern. CPF can be oxidized by various oxidizing agents, which give CPF-oxon after the replacement of sulfur by oxygen in the thiophosphoryl bond [4]. CPF-oxon is more toxic compared to its parent compound [5].

Nanotechnology offers fast and effective solutions for environmental cleanup. It has attracted considerable interest of both scientific and industrial communities because it is often described as an emerging technology capable of revolutionizing approaches to common problems [6]. Nanostructured membranes with size-selective pores may provide efficient ways of separating solutes from water [7]. Besides filtration, which is generally energy intensive, the removal of contaminants by sequestration (adsorptive remediation) or degradation to less toxic products (reactive remediation) may represent an effective alternative. Nanomaterials possess a very large surface-to-volume ratio that favors interaction with their environment. For example, nanomaterials have the potential to effectively adsorb molecules or catalyze chemical reactions at their interface [8]. Shahram et al. [9] 
showed that nanoparticle (NPs) form of zinc oxide ( $\mathrm{ZnO})$ was effective adsorbing agent for permethrin insecticide in water system, and the amount of reduction is related to permethrin concentration. For this reason, $\mathrm{ZnO}$ in the NP form could be an eminent candidate for preventing CPF adverse effects.

As per our knowledge, no work has been reported concerning the role of $\mathrm{ZnO}$, in the NP form against CPF toxicity in in vivo system. Hence, this work aimed to investigate the potential effects of this formulation to relieve the toxic effect of CPF on immune system prospecting its application industrially and medically to remove this insecticide from animal's water to decrease its toxicity. In addition, this work was employed to confirm that $\mathrm{ZnO}$ NPs have no harmful effects when it is added to the drinking water of the animals.

\section{Materials and Methods}

Ethical approval

The Institutional Animal Care and Use Committee (IACUC) of Cairo University approved the design of the experiment (IACUC protocol number: CU-II-S-50-17).

\section{Chemicals}

CPF was provided from Central Agricultural Pesticide Laboratory, National Center for Agricultural Research, Ministry of Agriculture, Giza, Egypt.

ZnO NPs $(100 \mathrm{~nm})$ were purchased from NanoTech, Dreamland, $6^{\text {th }}$ October, Giza, Egypt. Other chemicals were purchased from Sigma-Aldrich Chemicals Co., St. Louis, MO, USA, and Cusabio Biotech Co. Ltd.

\section{Animals}

Sixty mature male Sprague Dawley rats weighing $(180 \pm 10 \mathrm{~g})$ were used in this investigation. They were obtained from an animal house belonging to the Department of Veterinary Hygiene and Management, Faculty of Veterinary Medicine, Cairo University. Animals were maintained in plastic cages, fed on standard commercial pelleted feed and water that supplied ad libitum. They were observed for health status and were acclimated to the laboratory environment for 2 weeks before use.

\section{Experimental protocol}

Rats were randomly divided into four equal groups. The first group served as control, the second group received drinking water contained $75 \mathrm{mg} / \mathrm{L}$ $\mathrm{CPF}$, the third group received drinking water contained $75 \mathrm{mg} / \mathrm{L} \mathrm{CPF}$ and $200 \mathrm{mg} / \mathrm{L} \mathrm{ZnO} \mathrm{NPs}$, while the fourth group received drinking water contained $200 \mathrm{mg} / \mathrm{L} \mathrm{ZnO}$ NPs. The experiment was extended for 9 weeks. The selected concentration of CPF was nearly equivalent to ${ }^{1 /}$ of the $\mathrm{LD}_{50}[10]$, while the selected concentration of ZnO NPs was nearly equivalent to $30 \mathrm{mg} / \mathrm{kg}$ body weight which considered of no observable adverse effects [11]. Blood samples were collected every 3 weeks as will be mentioned, while at the end of the experimental period, animals of all groups were sacrificed under anesthesia using ketamine and xylazine $(40 \mathrm{mg} / \mathrm{kg}$ and $5 \mathrm{mg} / \mathrm{kg}$, respectively) intraperitoneally, thenliver and spleen were carefully dissected out, blotted free of blood and each organ was divided into two parts, one part was kept in $10 \%$ buffered neutral formalin for histopathological examination and the other was kept at $-20^{\circ} \mathrm{C}$ for further assessment of antioxidant markers.

\section{Immunological assessment}

Every 3 weeks, ten animals from each group were randomly selected for blood sample collection from the retro-orbital venous plexus under anesthesia using the mix of ketamine and xylazine $(40 \mathrm{mg} / \mathrm{kg}$ and $5 \mathrm{mg} / \mathrm{kg}$, respectively) IP. Blood samples were used for the assessment of macrophage activity after 1 and $2 \mathrm{~h}$ and comet assay on lymphocytes. In addition, serum samples were used to estimate the activity of serum lysozyme and the titer of interleukin-2 (IL-2) and IL-2.

\section{Determination of macrophage activity}

The amount of nitrite produced from isolated and cultivated macrophages during exposure to infection was determined by mixing the supernatant with the colorless Griess reagent forming a purple complex. The degree of the developed color was measured spectrophotometrically after 1 and $2 \mathrm{~h}$ using ELISA reader at $570 \mathrm{~nm}$ [12].

\section{Comet assay of lymphocytes}

DNA single-strand breaks (frank strand breaks and incomplete excision repair sites) were investigated at the single cell level using single-cell gel electrophoresis as previously mentioned by Tice et al. [13].

\section{Determination of serum lysozyme activity}

Lysozyme is an enzyme that is known to kill the organism through hydrolysis of their cell walls. Lysozyme enzyme was allowed to diffuse through the agarose gel containing a suspension of Micrococcus lysodeikticus as the substrate producing a clear zone ring of lysis on the agarose gel. At the end of the incubation period, the diameters of the clear zone rings were measured to the nearest $0.1 \mathrm{~mm}$ with an enlarger viewer (Kalesttad Laboratories., Inc., and Austin, TX). For each lysoplate, the lysozyme concentration in the samples was determined from a plotted standard curve against the corresponding clear zone ring diameter on the linear axis [14].

\section{Determination of serum IL-2 and IL-6}

The quantitative sandwich enzyme immunoassay technique was employed for the determination of IL-2 according to Goldsmith and Greene [15] and IL-6 according to Hirano [16]. Antibodies specific for IL-2 or IL-6 have been precoated onto microplates. Standards and samples were pipetted into the wells and, if the samples contain any IL-2 or IL-6, it will be bound by the immobilized antibody. Any 
unbound substance was removed, and then, a biotin-conjugated horseradish peroxidase was added to the wells. Any unbound avidin-enzyme reagent was washed followed by the addition of a substrate solution to the wells. The developed color will be in proportion to the amount of IL-2 or IL- 6 bound in the initial step. The color development was stopped, and the intensity of the color was measured.

\section{Determination of the antioxidant markers in liver and spleen tissues' homogenates}

Briefly, homogenization of liver and spleen tissue specimens was performed in $5-10 \mathrm{ml}$ cold buffer $(50 \mathrm{mM})$ of potassium phosphate $(\mathrm{pH} 7.5)$ and $1 \mathrm{mM}$ EDTA or $1 \mathrm{mM}$ EDTA per gram tissue for the determination of the lipid peroxidation marker; malondialdehyde (MDA) and glutathione (GSH) levels, respectively. Following centrifugation of the obtained homogenates at $5000 \mathrm{rpm}$ for $20 \mathrm{~min}$ at $4^{\circ} \mathrm{C}$, the supernatants were aspirated and transferred into Eppendorf Tubes and then preserved at $-80^{\circ} \mathrm{C}$ until used. Both MDA and GSH contents were assessed in the hepatic and splenic tissue homogenates according to Ellman [17] and Ruiz-Larrea et al. [18], respectively.

\section{Histopathological and immunohistochemical evaluation}

After fixation of liver and spleen specimens in $10 \%$ buffered neutral formalin for $72 \mathrm{~h}$, the specimens were washed, dehydrated in graded series of alcohol and cleared in xylol, and then embedded in paraffin. Serial sections of 4-5- $\mu \mathrm{m}$ thickness were obtained and stained with hematoxylin and eosin [19]. Electric light microscope Olympus BH2 (Tokyo, Japan) was used for the histopathological examination of hematoxylin and eosin sections.

Expression of ACHE in paraffin sections of hepatic tissue of all groups was demonstrated immunohistochemically according to the method described by Hsu et al. [20] using avidin-biotin-peroxidase (3,3-diaminobenzidine tetrahydrochloride [DAB], Sigma Chemical Co.).

After incubation of liver sections with monoclonal antibody for ACHE (Dako Corp, Carpinteria, CA) and reagents of avidin-biotin-peroxidase method (Vectastain ABC Peroxidase Kit, Vector Laboratories), antigen-antibody complex was detected. The immunoreactive cells were visualized using chromagen DAB (Sigma Chemical Co.). Following examination, the intensity of immunohistochemical staining of ACHE was quantified in random five high microscopic fields as an optical density using image analysis software (Image J, 1.46a, NIH, USA).

\section{Statistical analysis}

The results were expressed as mean \pm standard error of the mean. Data were analyzed using one-way analysis of variance followed by Duncan's multiple range test and GraphPad software CoStat. $\mathrm{p}<0.05$ was considered statistically significant.

\section{Results}

\section{Macrophage phagocytic activity}

Macrophages' activity of rats which received water contained $75 \mathrm{mg} / \mathrm{L} \mathrm{CPF}$ after 1 and $2 \mathrm{~h}$ from its cultivation showed a significant $(\mathrm{p}<0.05)$ decrease compared to the control group along the three periods (after 3, 6, and 9 weeks) of assessments, while macrophages' activity of those rats which received water contained $\mathrm{CPF}$ and $200 \mathrm{mg} / \mathrm{L} \mathrm{ZnO} \mathrm{NPs} \mathrm{was}$ significantly higher than that of CPF-intoxicated group along the experimental period. The activity of macrophages of $\mathrm{ZnO} \mathrm{NP}$-administrated group showed non-significant differences compared with that of control sets in the three periods' assessments (Figure-1a and b).

\section{Comet assay of Iymphocytes}

DNA degeneration percentage in control and the other treated groups is presented in Figure-2a. The nuclei of the lymphocyte cells of the control group in the last week of the experiment ( $9^{\text {th }}$ week) had no tail revealing intact DNA (Figure-2b). While those of rats received CPF, their DNA showed significant $(p<0.05)$ high degeneration percentage compared with the control group and many nuclei appeared with head and tail (Figure-2c). On the other hand, rats which drank water contained $\mathrm{CPF}$ and $\mathrm{ZnO}$ NPs (Figure-2d) revealed significant $(\mathrm{p}<0.05)$ lower DNA degeneration percentage compared with that observed in the CPF-intoxicated group. $\mathrm{ZnO} \mathrm{NP}$-administrated group revealed a non-significant difference from the control group.

\section{Serum lysozyme activity}

Serum lysozyme activity of CPF-intoxicated group showed significant $(\mathrm{p}<0.05)$ decrease when it compared with that of controls at each time point. The administration of $\mathrm{ZnO} \mathrm{NPs}$ to $\mathrm{CPF}$-intoxicated rats significantly $(\mathrm{p}<0.05)$ increased the lysozyme activity

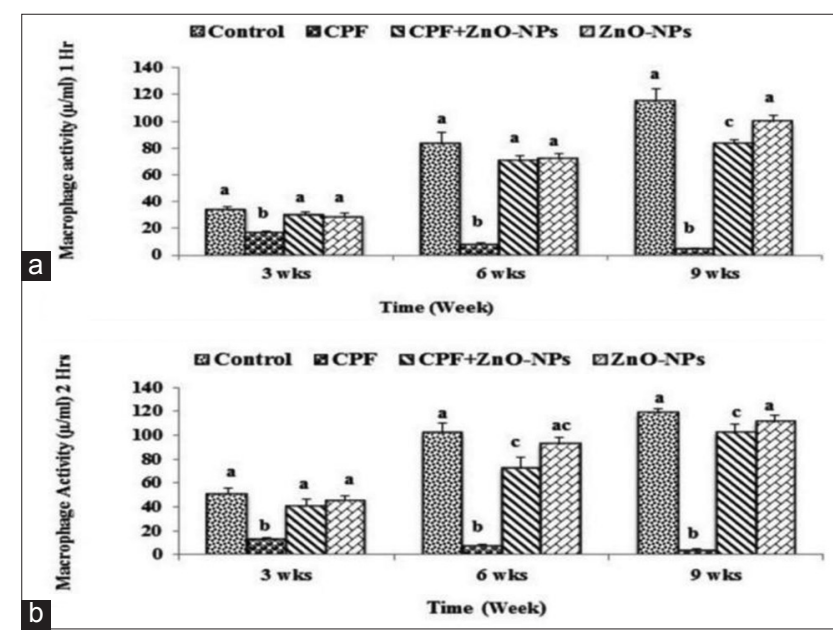

Figure-1: Mean values \pm standard error of the macrophage activity $(\mu \mathrm{M} / \mathrm{ml})$ after $1 \mathrm{~h} \mathrm{(a)}$ and $2 \mathrm{~h} \mathrm{(b)} \mathrm{from} \mathrm{its} \mathrm{cultivation}$ of control andexperimental rats which received water contained $75 \mathrm{mg} / \mathrm{L}$ chlorpyrifos and/or $200 \mathrm{mg} / \mathrm{L}$ zinc oxide nanoparticles. Columns have different scripts at the same time are significantly different at $p \leq 0.05(n=10)$. 


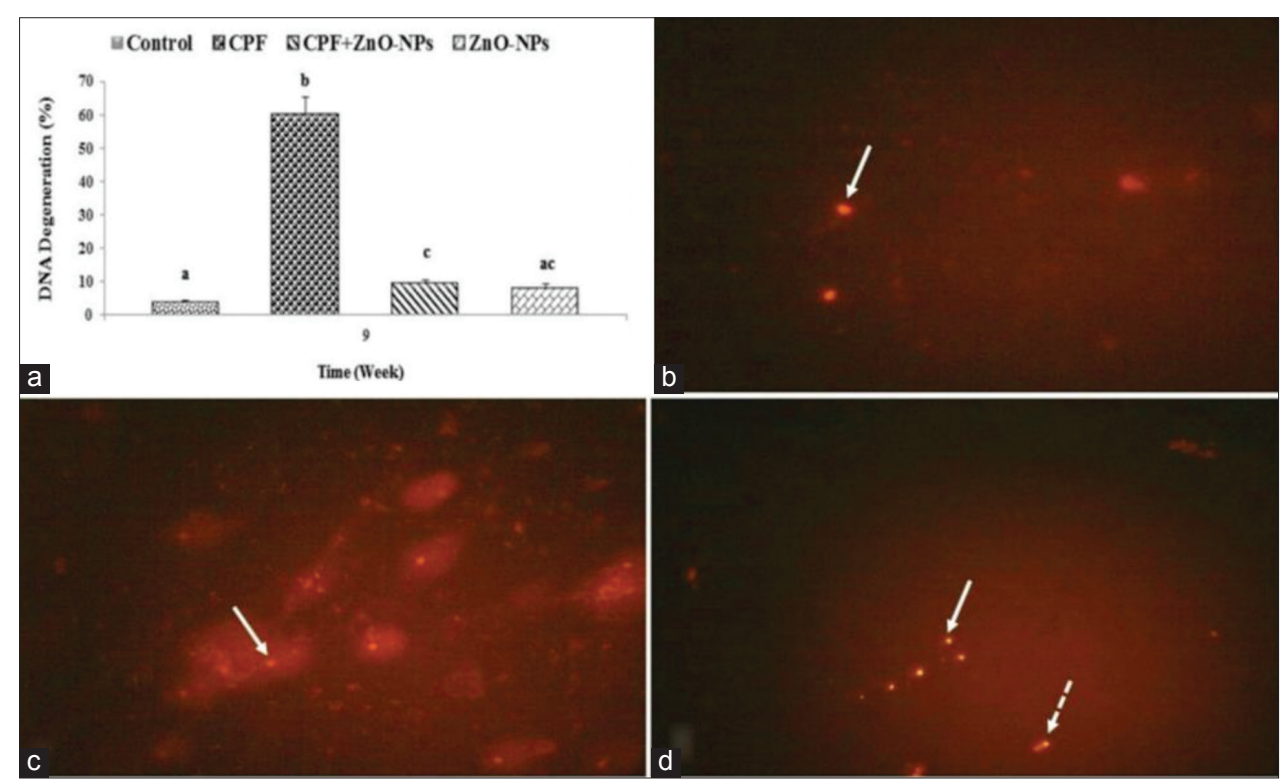

Figure-2: Comet assay of lymphocytes. (a) The mean values \pm standard error of the of DNA degeneration percentage of lymphocyte in all groups. (b-d) Nuclei of the lymphocytes of; (b) control rat have no tail (arrow) revealing intact DNA, (c) rats which received water contained chlorpyrifos (CPF) have head and tail (arrow) revealing many DNA breaks, (d) rat which received water contained combined CPF zinc oxide nanoparticles revealed many intact DNA that has no tail (arrow) and few DNA breaks which have head and tail (dashed arrow). Columns have different scripts at the same time are significantly different at $p \leq 0.05(n=10)$.

compared with that of CPF-intoxicated group particularly at the $6^{\text {th }}$ and $9^{\text {th }}$ weeks of assessment. Lysozyme activity of rats which received water contained $\mathrm{ZnO}$ NPs showed no difference from that of the controls (Figure-3a).

\section{Serum IL-2}

A gradual increase in serum IL-2 titer was recorded in the serum of control group along the periods of assessment $\left(3^{\text {rd }}, 6^{\text {th }}\right.$, and $9^{\text {th }}$ weeks $)$. However, serum IL-2 titer of rats intoxicated with CPF $(75 \mathrm{mg} / \mathrm{L})$ showed significant $(p<0.05)$ decrease compared with that of control and the other experimental groups. Rats which received water contained combination of CPF and $\mathrm{ZnO}$ NPs showed a significant increase in their IL-2 titer compared to that of CPF intoxicated rats, while serum titer of IL-2 of rats which administrated $\mathrm{ZnO} N \mathrm{Ns}$ in their drinking water showed no difference from the control group along the experimental period (Figure-3b).

\section{Serum IL-6}

Serum IL-6 titer of rats which administrated CPF showed a significant $(\mathrm{p}<0.05)$ decrease compared to that of controls at each time point. The titer of the group intoxicated with CPF and treated with ZnO NPs showed a significant $(p<0.05)$ increase compared with that of CPF-intoxicated group except at the $3^{\text {rd }}$ week of the experiment. Serum IL-6 titer for ZnO NPs-treated group showed a non-significant difference from that of the control group along the whole period of the experiment (Figure-3c).

\section{Oxidative stress markers}

Significant $(\mathrm{p}<0.05)$ elevation of both hepatic and splenic MDA levels (Figure-4a) accompanied with significant $(\mathrm{p}<0.05)$ reduction in their GSH content (Figure-4b) was observed in CPF-intoxicated rats compared with controls and those received $\mathrm{ZnO}$ NPs in their drinking water. The coadministration of $\mathrm{ZnO}$ NPs with CPF in the drinking water of rats exhibited a significant $(\mathrm{p}<0.05)$ recuperation of that altered oxidative stress markers by significant $(p<0.05)$ decrease in MDA level and a significant increase in GSH content.

\section{Histopathological and immunohistochemical findings}

Microscopic examination of the liver and spleen of normal control (Figure-5a and b) rats and those administrated $\mathrm{ZnO}$ NPs revealed normal histological structure (Figure-5c and d). Liver sections of CPFadministrated rats revealed congestion of the central veins and sinusoids (Figure-5e). Hepatic sinusoids were dilated and showed leukocytosis. Widespread hepatocellular vacuolar degeneration and necrosis were evident particularly in the centrilobular area (Figure-5f). The necrotic cells appeared with pyknotic or karyorrhectic nuclei or without any nuclear structure. Livers of rats received water contained combined $\mathrm{CPF}$ and $\mathrm{ZnO}$ NPs showed good protection of the hepatic parenchymal cells against the harmful effect of CPF with the only appearance of minimal degenerative changes (Figure-6a). The spleen of rats which received CPF in their drinking water showed a marked lymphocytic depletion of the white pulp lymphoid follicles with increased number of the tingible body macrophages and lymphocyte apoptosis (Figure-6b). Marked loss of lymphocytes in the germinal center with the appearance of the underlying reticular mash was observed (Figure-6c). The central arteriole showed thickened wall and focal areas of hyalinization. However, the spleens of combined 
$\mathrm{CPF}$ and $\mathrm{ZnO}$ NPs administrated rats showed minimal lymphocytic degeneration and necrosis (Figure-6d).

ACHE showed marked immunopositivity in the livers of control (Figure-7a) as well as $\mathrm{ZnO} \mathrm{NP}$ (Figure-7b) administrated rats, while the livers of rats which received CPF in their drinking water showed a significant $(\mathrm{p}<0.05)$ decreased expression of hepatic ACHE (Figure-7c). Thelatter decrease was significantly $(p<0.05)$ restored on the combined use of $\mathrm{ZnO}$ NPs with CPF (Figure-7d) as detected by the quantitative analysis of ACHE immune expression in various groups (Figure-7e).

\section{Discussion}

CPF is a broad-spectrum anticholinesterase insecticide, utilized extensively in agriculture and residential pest control throughout the world [21].

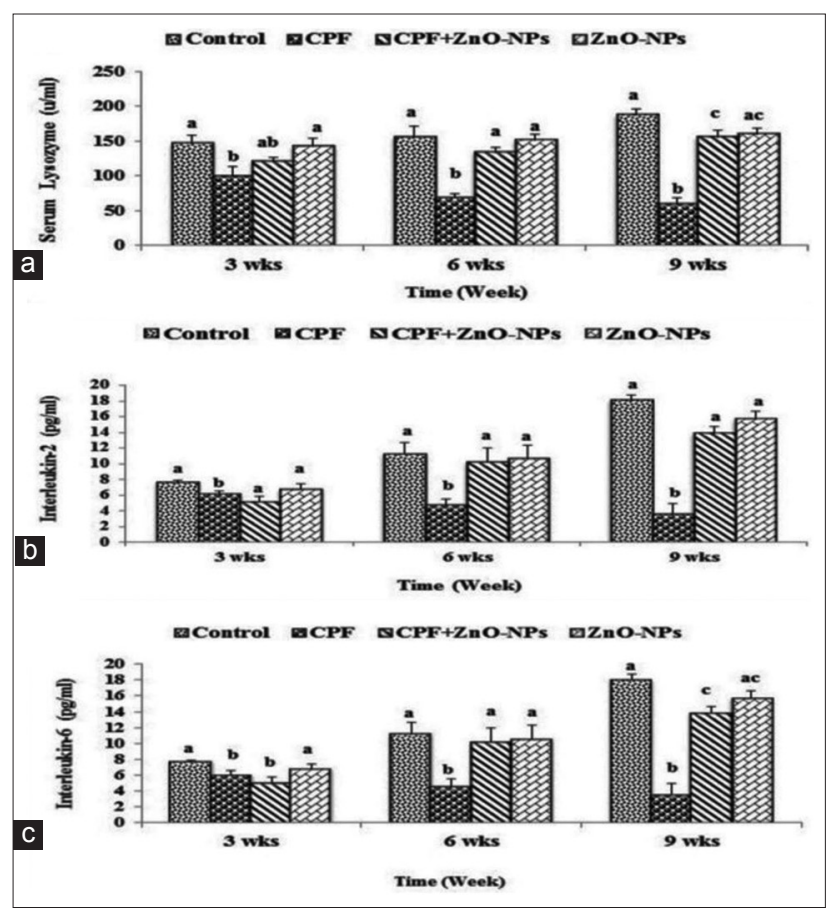

Figure-3: Mean values \pm standard error of (a) serum lysozyme activity $(\mathrm{u} / \mathrm{ml}),(b)$ interleukin-2 (IL-2) titer $(\mathrm{pg} /$ $\mathrm{ml})$, and (c) $\mathrm{IL}-2(\mathrm{pg} / \mathrm{ml})$ in control and experimental groups which received water contained $75 \mathrm{mg} / \mathrm{L}$ chlorpyrifos and/ or $200 \mathrm{mg} / \mathrm{L}$ zinc oxide nanoparticles. Columns having different scripts at the same time are significantly different at $p \leq 0.05(n=10)$.
Monitoring studies conducted in different countries revealed the presence of residues of this insecticide in different varieties of food commodities [22,23]. Moreover, CPF was also cytotoxic and immunotoxic even at lower concentration [24].

$\mathrm{ZnO}$ NPs physically showed effective adsorbing property for some insecticides [9]. The present study was conducted to follow up the protective efficacy of $\mathrm{ZnO}$ NPs (100 nm) against CPF immunotoxicity in male rats when they left to gain access to CPFcontaminated drinking water.

In the current study, cellular immune response of male rats was significantly reduced as a result of drinking water contaminated with $75 \mathrm{mg} / \mathrm{L}$ CPF. The recorded immunotoxic effects of CPF could be attributed to its direct toxic effect on blood cells as recorded by significant low percentages of phagocytic activity of macrophages after 1 and 2 h from its cultivation and serum lysozyme activity or indirectly on the hematopoietic organs as observed by the histopathological and immunohistochemical alterations in liver and spleen.

Despite CPF is ACHE inhibitor, its adverse effects are not only confined to cholinergic system but also to other body systems. Many studies elucidated that CPF exerted several adverse effects including hemotoxicity, immunological abnormalities as well as hepatic and renal dysfunctions [25-27]. Other studies revealed leukopenia apparently due to lymphopenia, neutropenia, and monocytopenia in the CPFadministrated animals $[25,28]$ and oxidative stress as well [29]. In the present investigation, immunotoxic manifestations induced by CPF may be associated with the enhanced production of reactive oxygen species (ROS), which cause damage to various membrane components of the cells of the immune system. Mansour et al. [27] identified ROS as a cause of toxic effects exerted by organophosphorus pesticides. These ROS are responsible for inducing oxidative stress in the tissues and chronic permanent damage.

Comet assay of the lymphocytes in the present study showed a general trend of increased DNA degeneration in the $\mathrm{CPF}$-intoxicated rats when it compared with the control and the other experimental groups. ROS produced due to CPF toxicity [21] could be

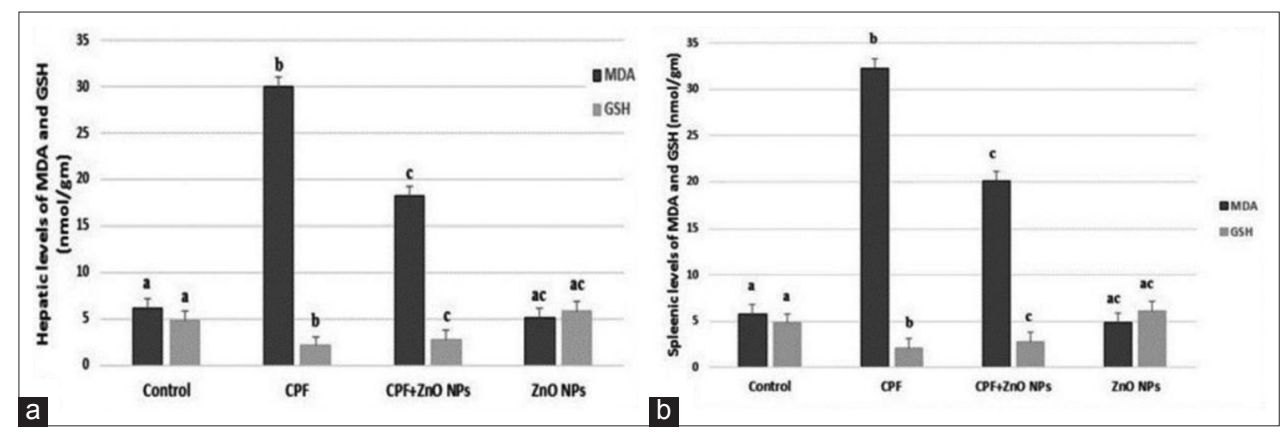

Figure-4: Mean valueststandard error of hepatic and splenic contents of (a) malondialdehyde and (b) glutathione in control and experimental groups which received water contained $75 \mathrm{mg} / \mathrm{L}$ chlorpyrifos and/or $200 \mathrm{mg} / \mathrm{L}$ nanoparticles of zinc oxide. Columns having different scripts at the same time are significantly different at $p \leq 0.05(n=10)$. 


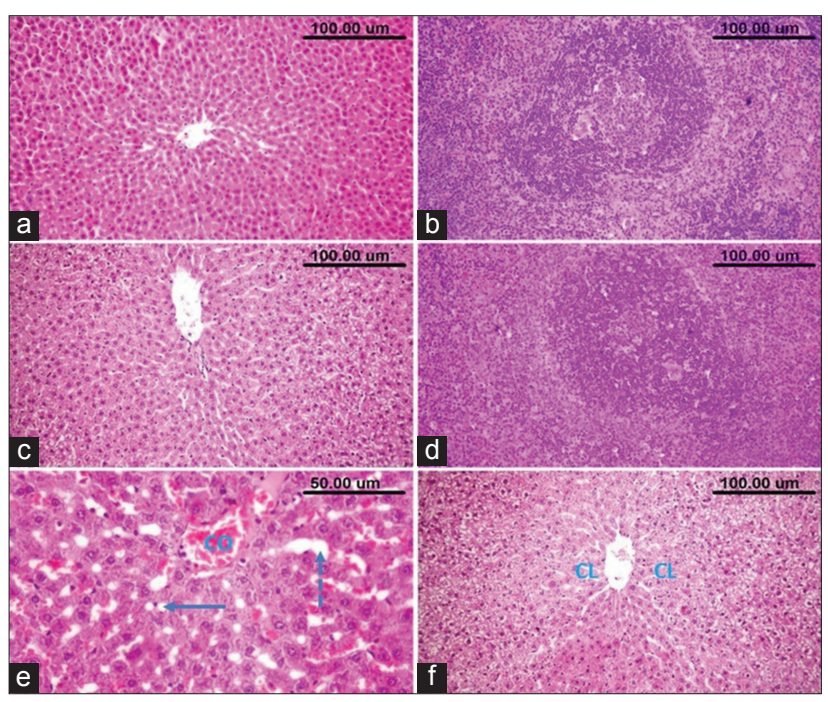

Figure-5: The liver and spleen of normal control ( $a$ and $b$ ) and nanoparticles of zinc oxide-administrated rats (c and d). (e and f) The liver of chlorpyrifos-administrated rats showing; (e) congestion of central vein ( $\mathrm{CO})$, dilatation of hepatic sinusoids (dashed arrow) and (e) and (f) centrilobular (CL) hepatocellular degeneration and necrosis.

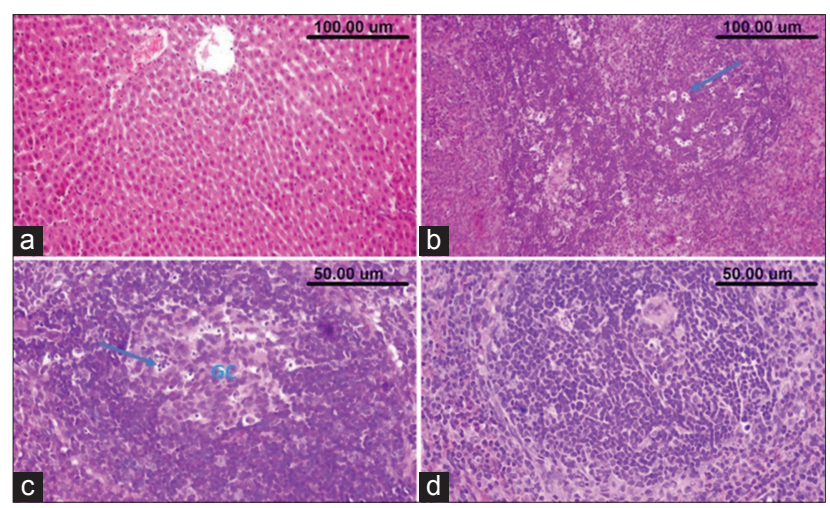

Figure-6: (a) The liver of chlorpyrifos (CPF) and nanoparticles of zinc oxide ( $\mathrm{nnO}$ NPs) administrated rat showing minimal degenerative changes in the hepatic parenchymal cells. (b and c) Spleen of rat which received CPF showing lymphocytic depletion with many tingible body macrophages (arrow) and lymphocytes apoptosis in the follicles, loss of the lymphocytes in the germinal center with appearance of the underlying reticular mash. (d) The spleen of combined CPF and ZnO NP-administrated rat showing minimal lymphocytic necrosis.

elicited detrimental DNA damage. Many reports have identified two potential cellular targets for CPF, cell signaling cascades from one side and the expression and function of gene transcription factors from the other side [30]. Oxidative stress is known to be a key factor in several diseases. In fact, one of the molecular mechanisms of some pesticides' toxicity seems to be lipid peroxidation; as a consequence, these compounds can disturb the biochemical and physiological functions of the immune system cells as well as the liver and kidney [31]. The current results illustrated that CPF had a strong inhibitory effect on both IL-2 and IL-6; these cytokines stimulate T-lymphocyte proliferation and stimulate the activities of T-helper cells and cytotoxic T-cells. They also induce the

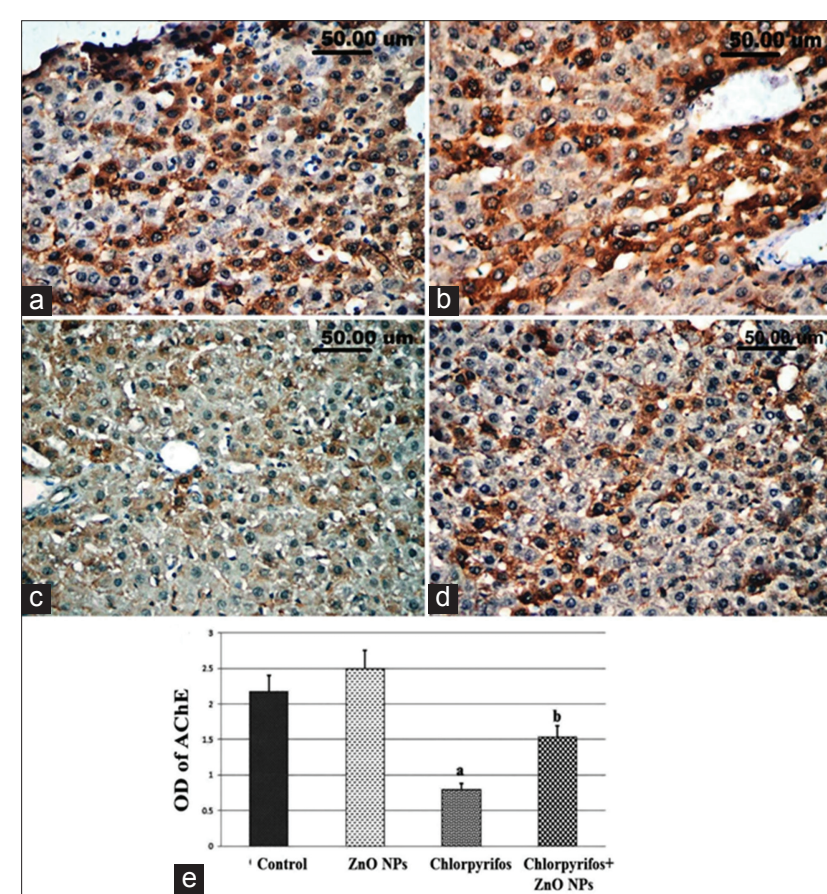

Figure-7: Acetylcholinesterase ( $\mathrm{ACHE}$ ) immune expression in the liver of control (a) and experimental groups which received water contained $200 \mathrm{mg} / \mathrm{L}$ nanoparticles of zinc oxide (ZnO NPs) (b), 75 mg/L chlorpyrifos (c), and combined CPE and ZnO NPs (d). (e) The quantitative image analysis of ACHE immune expression in various groups expressed as optical density in 5 microscopic fields. a: significantly different from control group at $p<0.05$, b: significantly different from chlorpyrifos group at $p<0.05$.

differentiation of Th1 cells and inhibit the differentiation of Th2 cells to regulate immune response [32]. Similar studies showed that CPF had an inhibitory effect on both IL-2 and interferon- $\gamma$ production on rats [28] and also CPF suppressed T-lymphocyte proliferation and reduced serum IgG and IgM levels in rats $[26,33]$.

As demonstrated by the microscopic examination, $\mathrm{CPF}$ exerted marked histological alterations in the examined liver and spleen tissues which could be attributed to the formation of ROS by CPE exposure. It had been reported that biologically active substances such as pesticides boost the formation of ROS which is responsible for the actuating oxidative stress in the tissues and subsequently their damage $[34,35]$. In addition, some studies identified ROS as a cause of toxic effects exerted by CPF as it increased oxidative stress in different tissues and organs [36,37] which supported with our results of increased hepatic and splenic contents of MDA and decreased their GSH contents. However, the addition of $\mathrm{ZnO}$ NPs to the drinking water contained CPF and markedly relieved the tissue alterations exerted by CPF. In this regard, several studies have demonstrated that zinc possesses antioxidant properties and consequently can protect the body cells from oxidative damage induced by certain xenobiotics [38]. In addition, zinc plays an essential role in cellular GSH regulation which is a vital process to cellular antioxidant defense, thus 
protecting the cell against ROS induced by OP pesticides [31]. The protective effect of zinc could be achieved through its interaction with cell membranes, thus stabilizing them against various damaging effects, including those caused by oxidative injuries.

ACHE expression was significantly decreased in the liver of CPF-administrated rats. CHE is known to be synthesized mainly in hepatocytes and then secreted into the bloodstream [39]. As a result of liver dysfunction, CHE synthesis and activity will be declined in comparison with the other serum hepatic function enzymes that related to the clinical assessment of liver function whose levels increased due to their increased release from their cellular sources following damage of cell membrane [40].

Like other organophosphorus insecticides, $\mathrm{CPF}$ is an ACHE enzyme inhibitor which leads to the accumulation of acetylcholine and results in excessive stimulation of postsynaptic receptors and consequent signs of toxicity [41]. CPF does not directly inhibit ACHE enzyme; it is first metabolized to the corresponding oxygen analog (CPF-oxon), a more potent inhibitor of ACHE enzyme. The activation of CPF into CPF-oxon is mediated by cytochrome $\mathrm{P}_{450}$ mixed function oxidases, primarily within the liver [42]; however, extrahepatic metabolism has been reported in other tissues including the brain [21]. Short-term exposure of CPF in rats caused a significant inhibition of ACHE enzyme activity in different tissues including the liver, kidney, and spleen [27].

The current results demonstrated that all the recorded CPF adverse effects on the immune system of male rats were significantly relieved by addition of $\mathrm{ZnO}$ NPs $(200 \mathrm{mg} / \mathrm{L})$ to the contaminated water. These findings suggested that $\mathrm{ZnO}$ NPs directly alleviated these effects by adsorbing CPF and consequently preventing it from inducing its toxic effect on the immune system. That adsorbing process is chiefly occurred as a result of the electrostatic attraction between negatively charged CPF anions and positively charged surface of the sorbent [43]. Another mechanism of $\mathrm{ZnO}$ NPs for alleviating the toxic effects of $\mathrm{CPF}$ in this research could be attributed to the antioxidant effect of ZnO NPs. As one of the essential nutrients, zinc can protect against oxidative damage caused by certain xenobiotics and thus may have antioxidant properties. It acts as a cofactor for important enzymes involved in the proper functioning of the antioxidant defense system $[38,44]$. Exposure to $\mathrm{ZnO}-\mathrm{NPs}$ in this study does not affect the exploratory behaviors of male rats. A similar finding was recorded by Soheili et al. [45] and Amara et al. [46].

\section{Conclusion}

The present results concluded that the coadministration of $\mathrm{ZnO}$ in the NP form to CPFcontaminated drinking water restored the viability and function of the immune cells, the oxidative stress markers, the histopathological alterations as well as the immune-expression of ACHE. These results give light on the beneficial use of ZnO NPs in CPFcontaminated water and in individuals who are occupationally on daily exposure to low concentration of such insecticide.

\section{Authors' Contributions}

EME and OSE designed the study and analyzed the data. IMG and SSAE contributed to the reagents/ materials/analysis tools and analyzed the data. SSE contributed to the reagents/materials/analysis tools, collected the material, and analyzed the data. All authors read and approved the final manuscript.

\section{Acknowledgments}

We thank the Immune section at the Research Institute for Animal Reproduction, Cairo, Egypt as well as Faculty of Veterinary Medicine, Cairo University, Egypt for providing all facilities to conduct this study. This research did not receive any specific grant from funding agencies in the public, commercial, or not-for-profit sectors.

\section{Competing Interests}

The authors declare that they have no competing interests.

\section{Publisher's Note}

Veterinary World remains neutral with regard to jurisdictional claims in published institutional affiliation.

\section{References}

1. Carvalho, F.P. (2017) Pesticides, environment, and food safety. Food Energy Secur., 6(2): 48-60.

2. LaKind, J.S., Sobus, J.R., Goodman, M., Barr, D. B., Furst, P., Albertini, R.J., Arbuckle, T.E., Schoeters, G., Tan, Y.M., Teeguarden, J., Tornero-Velez, R. and Weisel, C.P. (2014) A proposal for assessing study quality: Biomonitoring, environmental epidemiology, and shortlived chemicals (BEES-C) instrument. Environ. Int., 73(12): 195-207.

3. Antonio, V., Sergio, H., Martha, R. and Irmene, O. (2014) Detection of residual organochlorine and organophosphorus pesticides in agricultural soil in Rio Verde region of San Luis Potosi, Mexico. J. Environ. Sci. Health B., 49(7): 498-504.

4. Duirk, S.E., Desetto, L.M. and Davis, G.M. (2009) Transformation of organophosphorus pesticides in the presence of aqueous chlorine: Kinetics, pathways, and structure-activity relationships. Environ. Sci. Technol., 43(7): 2335-2340.

5. Lee, I., Eriksson, P., Fredriksson, A., Buratovic, S. and Viberg, H. (2015) Developmental neurotoxic effects of two pesticides: Behavior and biomolecular studies on chlorpyrifos and carbaryl. Toxicol. Appl. Pharmacol., 288(3): 429-438.

6. Shannon, M.A. (2008) Science and technology for water purification in the coming decades. Nature, 452(7185): 301-310.

7. Yang, H.Y. (2013) Carbon nanotube membranes with ultrahigh specific adsorption capacity for water desalination and purification. Nat. Commun., 4(8): 2220-2221.

8. Yuan, J. (2008) Super wetting nanowire membranes for 
selective absorption. Nat. Nanotechnol., 3(6): 332-336.

9. Shahram, M.D., Bahar, R., Ali, M.M.; Parviz, A.A. (2014) Removal of permethrin pesticide from water by chitosan zinc oxide nanoparticles composite as an adsorbent. $J$. Saudi Chem. Soc., 18(4): 348-355.

10. USEPA. (2000) Toxicology Chapter for Chlorpyrifos. A Report of United State Environmental Protection Agency, Washington DC 20460: 1-52 USA.

11. Kim, Y.R, Park, J.I, Lee, E.J., Park, S.H., Seong, N.W., Kim, J.H., Kim, G.Y., Meang, E.H., Hong, J.S., Kim, S.H, Koh, S.B. and Kim, M.S. (2014) Toxicity of $100 \mathrm{~nm}$ zinc oxide nanoparticles: A report of 90 days repeated oral administration in Sprague Dawley rats. Int. J. Nanomed., 9(2): 109-126.

12. Rajarman, V., Nonnecke, B., Franklin, S., Hamell, D. and Horst, R. (1998) Effect of Vitamin A and E on nitric oxide production by blood mononuclear leukocytes from neonatal calves fed on milk replacer. J. Dairy Sci., 81(12): 3278-3285.

13. Tice, R.R, Agurell, E., Anderson, D., Burlinson, B., Hartmann, A., Kobayashi, H., Miyamae, Y., Rojas, E., Ryu, J.C. and Sasaki, Y.F. (2000) Single cell gel/comet assay: Guidelines for in vitro and in vivo genetic toxicology testing. Environ. Mol. Mutagen., 35(3): 206-221.

14. Schultz, L.A. (1987) Lysozyme. In: Methods in Clinical Chemistry. Pesce, A.J. and Kaplan, L.A., editors. Mosby, St, Louis. p742-746.

15. Goldsmith, M.A. and Greene, W.C. (1994) In: Thomson, A., editor. The Cytokine Handbook. $2^{\text {nd }}$ ed. Academic Press, New York. p57-66.

16. Hirano, T. (1998) "Interleukin 6" in The Cytokine Handbook. $3^{\text {rd }}$ ed. Academic Press, New York. p197-210.

17. Ellman, G.L. (1959) Tissue sulfhydryl groups. Arch. Biochem. Biophys., 82(1): 70-77.

18. Ruiz-Larrea, M.B., Leal, A.M., Liza, M., Lacort, M. and de Groot, H. (1994) Antioxidant effects of estradiol and 2-hydroxyestradiol on iron-induced lipid peroxidation of rat liver microsomes. Steroids, 59(6): 383-388.

19. Bancroft, J.D. and Gamble, M. (2008) Theory and Practice of Histological Techniques. $6^{\text {th }}$ ed. Churchill Livingstone, Elsevier, China.

20. Hsu, S.M., Raine, L. and Fanger, H. (1981) The use of antiavidin antibody and avidin-biotin-peroxidase complex in immunoperoxidase technics. J. Clin. Pathol., 75(6): 816-821.

21. Xu, M.Y., Sun, Y.J. and Wang, P. (2015) Metabolomics analysis and biomarker identification for brains of rats exposed subchronically to the mixtures of low-dose cadmium and chlorpyrifos. Chem. Res. Toxicol., 28(6): 1216-1223.

22. Akan, J.C, Jafiya, L., Mohammed, Z. and Abdulrahman, A. (2013) Organophosphorus pesticide residues in vegetables and soil samples from Alau dam and Gongulong agricultural areas, Borno State, Nigeria. Int. J. Environ. Monit. Anal., 1(2): 58-64.

23. Al-Naggar, Y., Codling, G., Vogt, A., Naiem, E., Mohamed, M., Seif, A. and John, P. (2015) Organophosphorus insecticides in honey pollen and bees (Apis mellifera L.) and their potential hazard to bee colonies in Egypt. Ecotoxicol. Environ. Saf., 114(1): 1-8.

24. Gultekin, F., Patat, S., Akca, M. and Akdogan, M. (2006) Melatonin can suppress the cytotoxic effect of chlorpyrifos on human Hep G2 cell lines. Hum. Exp. Toxicol., 35(2): 47-55.

25. Uchendu, C., Ambali, S.F., Ayo, J.O. and Esievo, K.A. (2011) Acetyl-L-carnitine attenuates haemotoxicity induced by subacute chlorpyrifos exposure in Wistar rats. Der. Pharm. Let., 3(2): 292-303.

26. Hamza, R.Z., Diab, A.Z., Abd El-Aziz, E.A. and Hendawy, A.A. (2013) Immunotoxic effect of organophosphorus insecticides chlorpyrifos, profenofos, and possible ameliorative role of propolis and ginseng. Biosci. Biotech. Res. Asia, 10(2): 645-651.
27. Mansour, S.A., Abbassy, M.A. and Shaldam, H.A. (2017) Hepato-renal toxicity induced by chlorpyrifos, diazinon and their mixture to male rats with special concern to the effect of zinc supplementation. J. Toxicol. Pharmacol., 1(3): $15-24$.

28. Wang, P., Wang, J., Sun, Y., Yang, L. and Wu, Y. (2017) Cadmium and chlorpyrifos inhibit cellular immune response in spleen of rats. Environ. Toxicol., 32(7): 1927-1936.

29. Shittu, M., Ayo, J.O. and Ambali, S.F. (2012) Chronic chlorpyrifos-induced oxidative changes in the testes and pituitary gland of Wistar rats: Ameliorative effects of Vitamin C. Pestic. Biochem. Physiol., 102(1): 79-85.

30. Lee, Y.S., Lewis, J.A., Ippolito, D.L., Hussainzada, N., Lein, P.J., Jackson, D.A. and Stallings, J.D. (2016) Repeated exposure to neurotoxic levels of chlorpyrifos alters hippocampal expression of neurotrophins and neuropeptides. Toxicology, 340(1): 53-62.

31. Mansour, S.A. and Mossa, A.H. (2010) Oxidative damage, biochemical and histological alterations in rats exposed to chlorpyrifos and the antioxidant role of zinc. Pestic. Biochem. Physiol., 96(1): 14-23.

32. Henney, C.S., Kuribayashi, K., Kern, D.E. and Gillis, S. (1981) IL-2 augments natural killer cell activity. Nature, 291(5813): 335-338

33. Gajewski, T.F., Joyce, J. and Fitch, F.W. (1989) Antiproliferative effect of IFN-gamma in immune regulation. III. Differential selection of TH1 and TH2 murine helper T-lymphocyte clones using recombinant IL-2 and recombinant IFN. J. Immunol., 143(1): 15-22.

34. Akhgari, M., Abdollahi, M., Kebryaeezadeh, A., Hosseini, R. and Sabzevari, O. (2003) Biochemical evidence for free radical-induced lipid peroxidation as a mechanism for subchronic toxicity of Malathion in blood and liver of rats. Hum. Exp. Toxicol., 22(4): 205-211.

35. Abdollahi, M., Mostafalou, S., Pournourmohammadi, S. and Shadnia, S. (2004) Oxidative stress and cholinesterase inhibition in saliva and plasma of rats following subchronic exposure to Malathion. Comp. Biochem. Physiol. C. Toxicol. Pharmacol., 137(1): 29-34.

36. Verma, R.S., Mehta, A. and Srivastava, N. (2007) In vivo chlorpyrifos induced oxidative stress: Attenuation by antioxidant vitamins. Pestic. Biochem. Physiol., 88(1): 191-196.

37. Kalender, Y., Kaya, S. and Durak, D. (2012) Protective effects of catechin and quercetin on antioxidant status, lipid peroxidation and testis-histoarchitecture induced by chlorpyrifos in male rats. Environ. Toxicol. Pharmacol., 33(2): 141-148.

38. Powell, S.R. (2000) The antioxidant properties of zinc. J. Nutr., 130(5S): 1447S-1454S.

39. Brown, S.S., Kalow, W., Pilz, W., Whittaker, M. and Woronick, C.L. (1981) The plasma cholinesterases: A new perspective. Adv. Clin. Chem., 22(3): 1-123.

40. Moss, D.M, Henderson, A.R. and Tietz, T. (1999) Textbook of Clinical Enzymology, Clinical Enzymology. In: Burtis, C.A. and Ashwood, E.R., editors. WB Saunders Co, Philadelphia, PA, USA. p617-721.

41. Zheng, Q., Oliver, K., Won, Y.K. and Pope, C.N. (2000) Comparative cholinergic neurotoxicity of chlorpyrifos exposure in pre-weaning and adult rats. Toxicol. Sci., 55(1): 124-132.

42. An, X., Ji, X., Wu, M., Hu, X., Yu, R., Zhao, X., and Cai, L. (2014) Risk assessment of applicators to chlorpyrifos through dermal contact and inhalation at different maize plant heights in China. J. Agric. Food Chem., 62(29): 7072-7077.

43. Rengarag, S., Moon, S.H. and Sivabalan, R. (2002) Agricultural solid waste for the removal of organics from water and waste water by palm seed coated activated carbon, Waste Manage., 22(5): 543-548.

44. Cruz, K.J., Morai, J.B., de Oliveira, A.R., Severo, J.S. and Marreiro, D.N. (2017) The effect of zinc supplementation on insulin resistance in obese subjects: A systematic review. 
Biol. Trace Elem. Res., 176(2): 239-243.

45. Soheili, S., Saeed, M., Attaollah, S. and Masoud, G. (2013) Histopathological effects of $\mathrm{ZnO}$ nanoparticles on liver and heart tissues in Wistar rats. Adv. Biores., 4(2): 83-88.
46. Amara, S., Ben-Slama, I., Mrad, I., Rihane, N. and Jeljeli, M. (2014) Acute exposure to zinc oxide nanoparticles does not affect the cognitive capacity and neurotransmitters levels in adult rats. Nanotoxicology, 8(Suppl 1): 208-215.

$* * * * * * * *$ 